\title{
Pengaruh Disiplin Kerja Dan Motivasi Kerja Terhadap Kinerja Karyawan Pada Rumah Sakit Umum Tangerang Selatan
}

\author{
Suwanto \\ Dosen Fakultas Ekonomi Universitas Pamulang \\ Email:dosen01813@unpam.ac.id
}

\begin{abstract}
ABSTRAK
Tujuan yang ingin dicapai dalam penelitian ini adalah untuk mengetahui secara parsial maupun simultan pengaruh Pengaruh Disiplin Kerja dan Motivasi Kerja Terhadap Kinerja Karyawan Pada Rumah Sakit Umum Tangerang Selatan.

Metode penelitian ini merupakan penelitian asosiatif dengan menggunakan pendekatan kuantitatif. Subjek penelitian ini seluruh karyawan Rumah Sakit Umum Kota Tangerang Selatan sebanyak 57 karyawan. Sedangkan sampel yang dipergunakan sebanyak 57 responden dengan menggunakan Teknik sampel jenuh. Pengumpulan data menggunakan wawancara, kuesioner, dokumentasi, dan studi kepustakaan. Sedangkan analisis data menggunakan uji validitas, uji reliabilitas, uji normalitas, uji multikorelasi, uji heteroskedastisitas, regresi linear, koefisien determinasi, dan uji signifikan (uji t dan uji F).

Berdasarkan hasil penelitian, Nilai thitung untuk variabel Disiplin Kerja (X1) terhadap Kinerja (Y) adalah 7,524 > 1,673 dapat disimpulkan bahwa variabel Disiplin Kerja mempunyai pengaruh yang signifikan terhadap Kinerja. Nilai thitung untuk Variabel Motivasi Kerja (X2) terhadap Kinerja (Y) adalah sebesar 9,879, jadi $0,829<1,673$ dapat disimpulkan variabel Motivasi mempunyai pengaruh yang positif terhadap Kinerja. Diperoleh model persamaan regresi linear berganda $\mathrm{Y}=$ $5,103+0,171 \mathrm{X} 1+0,028 \mathrm{X} 2$. Nilai R sebesar 0,809 atau $80,9 \%$ yang berarti korelasi Disiplin Kerja dan Motivasi Kerja terhadap Kinerja pada kategori Kuat (0,600 0,800) dengan nilai koefisien determinasi adjusted R2 (adjusted R Square) sebesar 0.641. Hal ini menunjukan bahwa sebesar 64,1\% Disiplin Kerja dan Motivasi Kerja secara simultan (bersama-sama) mempengaruhi Kinerja karyawan, sedangkan sisanya sebesar $35,9 \%$ dipengaruhi oleh faktor lainnya yang tidak diteliti dalam penelitian ini.
\end{abstract}

Kata Kunci : Disiplin Kerja, Motivasi Kerja, Kinerja Karyawan 


\section{PENDAHULUAN}

\section{A. Latar Belakang}

Sumber daya manusia sebagai unsur utama pada suatu lembaga memiliki peranan yang sangat besar dalam upaya mencapai tujuan yang telah ditetapkan. Peran sumber daya manusia ini kemudian berkembang mengikuti perkembangan organisasi, ilmu pengetahuan dan teknologi. Sumber daya manusia memegang peranan yang sangat menentukan karena bagaimanapun hebat dan canggihnya teknologi yang digunakan tanpa didukung oleh manusia sebagai pelayan operasionalnya, tidak akan mampu menghasilkan suatu output yang sesuai dengan tingkat efisiensi yang tinggi. Oleh karna itu pengembangan sumber daya manusia dalam suatu organisasi menjadi sangat penting, semua itu dimulai dari disiplin.

Disiplin yang baik mencerminkan besarnya rasa tanggung jawab seseorang terhadap tugas-tugasnya yang diberikan kepadanya. Hal ini mendorong gairah kerja, dan terwujudnya tujuan perusahaan, karyawan, dan masyarakat. Oleh karena itu, setiap manajer selalu berusaha agar pada bawahannya mempunyai disiplin yang baik. Seorang manajer dikatakan efektif dalam kepemimpinannya, jika karyawannya berdisiplin baik. Untuk memelihara dan meningkatkan kedisiplinan yang baik adalah hal yang sulit. Karna banyak faktor yang mempengaruhinya.

Peraturan sangat diperlukan untuk memberikan bimbingan dan penyuluhan bagi karyawan Rumah Sakit Umum Kota Tangerang Selatan dalam menciptakan tata tertib yang baik, semangat kerja, moral kerja, efisiensi, dan efektivitas kerja karyawan akan meningkat. Jika karyawan Rumah Sakit Umum Kota Tangerang Selatan tidak mematuhi peraturanperaturan perusahaan tersebut, akan sulit mencapai tujuannya perusahaan. Kedisiplinan suatu perusahaan dikata baik, jika sebagian besar karyawan mentaati peraturan-peraturan yang ada.

Hasil observasi di Rumah Sakit Umum - Tangerang Selatan menyatakan bahwa ketidak disiplinan karyawan salah satunya tercermin dari karyawan yang tidak dapat menyelesaikan pekerjaan sesuai dengan waktu yang telah ditetapkan.

Untuk mendapatkan sumber daya manusia yang diharapkan oleh organisasi agar memberikan andil positif terhadap semua kegiatan perusahaan dalam mencapai tujuannya, setiap karyawan diharapkan memiliki motivasi kerja yang tinggi sehingga nantinya akan meningkatkan kinerja yang tinggi.

Rumah Sakit Umum Kota Tangerang Selatan yang berada di kota Tangerang Selatan merupakan salah satu instansi yang bergerak dalam bidang pelayanan kesehatan yang didirikan pada tahun 2010. Instansi ini melayani berbagai pelayanan seperti rawat jalan baik dokter umum maupun dokter spesialis, rawat inap, persalinan, operasi, rontgen, senam hamil dan sebagainya. Fasilitas yang dimiliki Rumah 
Sakit Umum Kota Tangerang Selatan ini tersedia UGD, berbagai poli dokter spesialis, ruang operasi, perina, HCU, laboratorium, ATM center, salon kecantikan, basement dan sebagainya. Di Rumah Sakit Umum Kota Tangerang Selatan ini terdapat praktek dokter seperti dokter spesialis kandungan, dokter spesialis anak, dokter spesialis penyakit dalam, dokter spesialis gigi, dokter spesialis bedah, dokter spesialis anastesi dan dokter umum. Pemberian motivasi masih dirasakan kurang optimal hal ini didasarkan pada kurang efektifnya pemberian penghargaan, sistem pemberian kompensasi yang kurang baik, perencanaan karir yang tidak diberikan secara efektif, kondisi kerja yang tidak menyenangkan, beberapa aspek tersebut tentunya berdampak pada kurang optimalnya kinerja karyawan yang mengakibatkan kurang semangatnya karyawan dalam melakukan pekerjaannya dan menurunnya disiplin kerja karyawan tersebut

\section{B. Identifikasi Masalah}

1. Kurangnya disiplin karyawan.

2. Masih banyak ditemukan karyawan yang datang terlambat.

3. Masih banyak karyawanyang tidak dapat menyelesaikan pekerjaan sesuai dengan waktu yang telah ditetapkan.

4. Kurangnya dorongan untuk membangkitkan motivasi karyawan.

5. Menurunya prilaku menjaga atau memelihara karyawan.

6. Kurangnya tanggung jawab karyawan.
7. Kinerja karyawan menurun.

\section{Rumusan Masalah}

1. Bagaimana pengaruh disiplin kerja terhadap kinerja karyawan pada Rumah Sakit Umum Kota Tangerang Selatan?

2. Bagaimana pengaruh motivasi kerja terhadap kinerja karyawan pada Rumah Sakit Umum Kota Tangerang Selatan?

3. Seberapa besar pengaruh disiplin dan motivasi secara simultan terhadap kinerja karyawan pada Rumah Sakit Umum Kota Tangerang Selatan?

\section{METODOLOGI PENELITIAN}

\section{A. Ruang Lingkup Penelitian}

1. Tempat Penelitian

Penelitian ini dilakukan di Rumah Sakit Umum Kota Tangerang Selatan, yang beralamat di Jalan Pajajaran No 101, Pamulang Barat Kota Tangerang Selatan.

\section{Waktu Penelitian dan Jadwal Penelitian}

Penelitian ini dilakukan pada bulan juli sampai dengan september 2019.

\section{B. Metode Populasi dan Sampel}

\section{Populasi}

Populasi dalam penelitian ini adalah Seluruh karyawan pada Rumah Sakit Umum Kota Tangerang Selatan yang berjumlah 57 orang.

2. Sampel

\begin{tabular}{|c|c|}
\hline Seluruh & populasi \\
\hline $\begin{array}{l}\text { digunakan sebagai } \\
\text { penelitian, yaitu } 57 \mathrm{k}\end{array}$ & $\begin{array}{r}\text { obyek } \\
\text { karyawan }\end{array}$ \\
\hline $\begin{array}{l}\text { Rumah Sakit Umun } \\
\text { Tangerang Selatan. }\end{array}$ & m Kota \\
\hline
\end{tabular}


C. Metode Analisis Data

1. Uji Validitas

2. Uji Reliabilitas

3. Uji Asumsi Klasik

a. Uji Normalitas

b. Uji Multikolinearitas

c. Uji Heteroskedastisitas

d. Uji Autokolerasi

4. Uji Hipotesis

a. Regresi Linier Berganda

b. Uji Koefisien Determinasi $\left(\mathbf{R}^{2}\right)$

c. Uji Statistik t (Parsial)

d. Uji Statistik F (Simultan)

HASIL PENELITIAN DAN

PEMBAHASAN

A. Hasil Penelitian

1. Uji Kualitas Data

a. Tabel 4.1 Uji Validitas Uji Validitas Variabel Disiplin Kerja (X1)

\begin{tabular}{|l|c|c|c|}
\hline Pernyataan & r $_{\text {hitung }}$ & $\mathrm{r}_{\text {tabel }}$ & Keterangan \\
\hline Dis_1 & 0,591 & 0,220 & Valid \\
\hline Dis_2 & 0,673 & 0,220 & Valid \\
\hline Dis_3 & 0,415 & 0,220 & Valid \\
\hline Dis_4 & 0,818 & 0,220 & Valid \\
\hline Dis_5 & 0,244 & 0,220 & Valid \\
\hline Dis_6 & 0,242 & 0,220 & Valid \\
\hline Dis_7 & 0,744 & 0,220 & Valid \\
\hline Dis_8 & 0,671 & 0,220 & Valid \\
\hline Dis_9 & 0,774 & 0,220 & Valid \\
\hline Dis_10 & 0,682 & 0,220 & Valid \\
\hline
\end{tabular}

\section{b. Tabel 4.2 Uji Validitas} Variabel Motivasi

$\operatorname{Kerja}(X 2)$

\begin{tabular}{|l|c|c|c|}
\hline Pernyataan & $\mathrm{r}_{\text {hitung }}$ & $\mathrm{r}_{\text {tabel }}$ & Keterangan \\
\hline Mot_1 & 0,659 & 0,220 & Valid \\
\hline Mot_2 & 0,780 & 0,220 & Valid \\
\hline Mot_3 & 0,726 & 0,220 & Valid \\
\hline Mot_4 & 0,741 & 0,220 & Valid \\
\hline Mot_5 & 0,815 & 0,220 & Valid \\
\hline Mot_6 & 0,333 & 0,220 & Valid \\
\hline Mot_7 & 0,405 & 0,220 & Valid \\
\hline
\end{tabular}

c. Tabel 4.3 Uji Validitas

Variabel Kinerja (Y)

\begin{tabular}{|c|c|c|c|}
\hline Pernyataan & $\mathrm{r}_{\text {hitung }}$ & $\mathrm{r}_{\text {tabel }}$ & Keterangan \\
\hline K_1 & 0,556 & 0,220 & Valid \\
\hline K_2 & 0,666 & 0,220 & Valid \\
\hline K_3 & 0,762 & 0,220 & Valid \\
\hline K_4 & 0,664 & 0,220 & Valid \\
\hline K_5 & 0,719 & 0,220 & Valid \\
\hline K_6 & 0,787 & 0,220 & Valid \\
\hline K_7 & 0,74 & 0,220 & Valid \\
\hline K_8 & 0,692 & 0,220 & Valid \\
\hline K_9 & 0,830 & 0,220 & Valid \\
\hline K_10 & 0,756 & 0,220 & Valid \\
\hline
\end{tabular}

2. Uji Asumsi Klasik a. Uji Normalitas Data

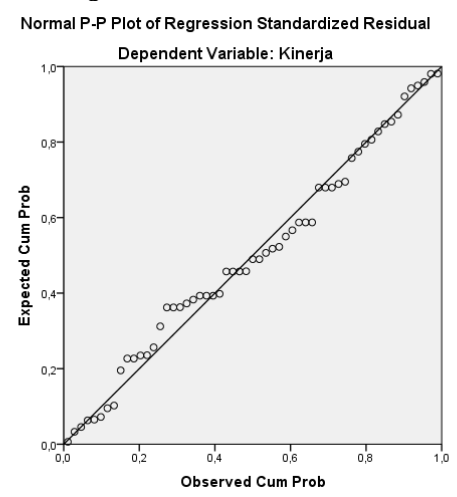

Gambar 4.2 P-P Plot Uji Normalitas

Tabel 4.4

Uji Normalitas

One-Sample Kolmogorov-Smirnov Test

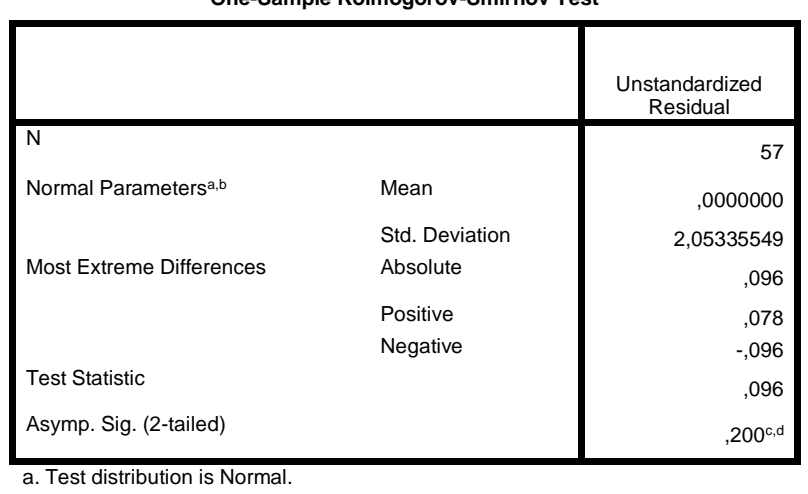

b. Calculated from data

c. Lilliefors Significance Correction.

d. This is a lower bound of the true significance. 
b. Uji Heteroskedastisitas Scatterplot

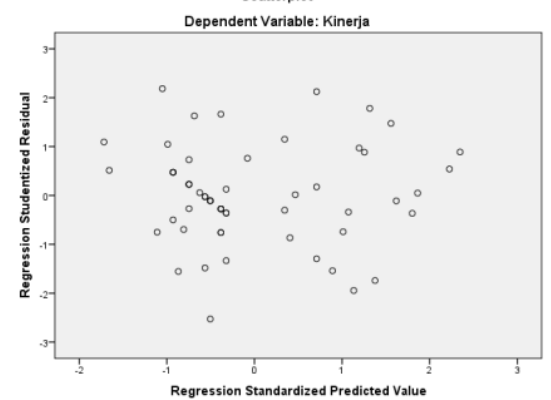

Gambar 4.3. Scatterplot

c. Uji Multikolinieritas

Tabel 4.5 Uji Multikolinearitas Coefficients ${ }^{\mathrm{a}}$

\begin{tabular}{|ll|r|r|}
\hline \multirow{2}{*}{ Model } & \multicolumn{2}{|c|}{$\begin{array}{c}\text { Collinearity } \\
\text { Statistics }\end{array}$} \\
\cline { 2 - 3 } & $\begin{array}{c}\text { Toler } \\
\text { ance }\end{array}$ & \multicolumn{1}{c|}{ VIF } \\
\hline $1 \quad$ (Constant) & & \\
& Disiplin &, 493 & 2,029 \\
\multicolumn{2}{|c|}{ Motivasi } &, 493 & 2,029 \\
\hline
\end{tabular}

a. Dependent Variable: Motivasi

3. Uji Hipotesis

a. Uji t

Tabel 4.6 Disiplin Kerja (X1) Terhadap Kinerja ( $Y$ )

Coefficients ${ }^{\mathrm{a}}$

\begin{tabular}{|c|c|c|c|c|c|}
\hline \multirow[b]{2}{*}{ Model } & \multicolumn{2}{|c|}{$\begin{array}{c}\text { Unstandardized } \\
\text { Coefficients }\end{array}$} & \multirow{2}{*}{\begin{tabular}{|c}
$\begin{array}{c}\text { Standardi } \\
\text { zed } \\
\text { Coefficien } \\
\text { ts }\end{array}$ \\
Beta
\end{tabular}} & \multirow[b]{2}{*}{$t$} & \multirow[b]{2}{*}{ Sig. } \\
\hline & B & $\begin{array}{l}\text { Std. } \\
\text { Error }\end{array}$ & & & \\
\hline $\begin{array}{ll}1 & \text { (Consta } \\
& \text { nt) }\end{array}$ & 7,101 & 4,239 & & 1,675 & 100 \\
\hline Kinerja & 1,094 & 145 & ,712 & 7,524 & ,000 \\
\hline
\end{tabular}

Tabel 4.7 Motivasi (X2) terhadap

Kinerja (Y)

Coefficients $^{a}$

\begin{tabular}{|c|c|c|c|c|c|}
\hline \multirow[b]{2}{*}{ Model } & \multicolumn{2}{|c|}{$\begin{array}{c}\text { Unstandardized } \\
\text { Coefficients }\end{array}$} & \multirow{2}{*}{$\begin{array}{c}\begin{array}{c}\text { Standar } \\
\text { dized } \\
\text { Coefficie } \\
\text { nts }\end{array} \\
\text { Beta } \\
\end{array}$} & \multirow[b]{2}{*}{$t$} & \multirow[b]{2}{*}{ Sig. } \\
\hline & B & $\begin{array}{l}\text { Std. } \\
\text { Error }\end{array}$ & & & \\
\hline \begin{tabular}{|ll}
1 & $\begin{array}{l}\text { (Const } \\
\text { ant) }\end{array}$
\end{tabular} & 6,319 & 3,587 & & $\begin{array}{r}1,76 \\
1\end{array}$ & ,084 \\
\hline $\begin{array}{l}\text { Motiva } \\
\text { si }\end{array}$ & 1,215 & 123 & ,800 & $\begin{array}{r}9,87 \\
9\end{array}$ & ,000 \\
\hline
\end{tabular}

a. Dependent Variable: Kinerja b. Uji Hipotesis Simultan (Uji F)

Tabel 4.8 Disiplin (X1), dan Motivasi (X2) terhadap Kinerja (Y)

ANOVA

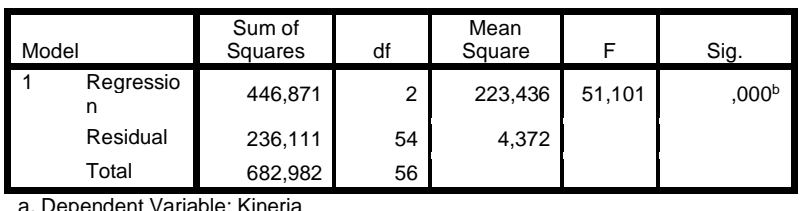

b. Predictors: (Constant), Motivasi, Disiplin

Dari hasil tabel diatas dapat dijelaskan bahwa pengaruh antara variabel Disiplin Kerja (X1), dan Motivasi Kerja (X2) secara simultan terhadap Kinerja (Y) positif dan signifikan karena nilai $F_{\text {hitung }}>$ nilai $\mathrm{F}_{\text {tabel }}$ yaitu $51,101>2,70$ dan nilai signifikan $<0,05$ sehingga Ho ditolak $\mathrm{Ha}$ diterima.

c. Analisis Regresi Linear Berganda

Tabel 4.9 Disiplin Kerja (X1), dan

Motivasi Kerja (X2) terhadap

Kinerja (Y)

Coefficients $^{a}$

\begin{tabular}{|c|c|c|c|c|c|}
\hline \multirow[b]{2}{*}{ Model } & \multicolumn{2}{|c|}{$\begin{array}{c}\text { Unstandardized } \\
\text { Coefficients }\end{array}$} & \multirow{2}{*}{$\begin{array}{c}\begin{array}{c}\text { Standardi } \\
\text { zed } \\
\text { Coefficien } \\
\text { ts }\end{array} \\
\text { Beta }\end{array}$} & \multirow[b]{2}{*}{$t$} & \multirow[b]{2}{*}{ Sig. } \\
\hline & B & $\begin{array}{l}\text { Std. } \\
\text { Error }\end{array}$ & & & \\
\hline $\begin{array}{ll}1 & \text { (Const } \\
\text { ant) }\end{array}$ & 5,103 & 3,635 & & 1,404 & 166 \\
\hline Disiplin & 171 & ,113 & ,173 & 1,518 & 135 \\
\hline $\begin{array}{l}\text { Motivas } \\
\mathrm{i}\end{array}$ & 1,028 & 173, & 677 & 5,936 & ,000 \\
\hline
\end{tabular}

Dari tabel diatas dapat diperoleh model persamaan regresi linear berganda sebagai berikut: $\mathrm{Y}=5,103+0,171 X 1+$ 1,028X2

Keterangan:

Y : Kinerja

$\mathrm{X}_{1} \quad$ : Disiplin Kerja

$\mathrm{X}_{2}$ : Motivasi Kerja 
Hasil persamaan regresi linear berganda tersebut dapat dilihat bahwa koefisien regresi yang diperoleh variabel Disiplin Kerja dan Motivasi Kerja mempunyai pengaruh positif terhadap Kinerja, artinya setiap ada peningkatan variabel Disiplin Kerja dan Motivasi Kerja akan meningkatkan pula Kinerja.

Adapun persamaan

tersebut dapat dijelaskan sebagai berikut :

1) Nilai konstanta intersep sebesar 5,103 merupakan nilai konstanta (a)

2) Nilai koefisien regresi variabel Disiplin terhadap Kinerja adalah sebesar 0,171. Hal ini berarti jika variabel Kepemimpinan naik 1 satuan akan meningkat variabel Kinerja sebesar 0,171, dengan asumsi variabel Disiplina dan Motivasi dianggap konstan.

3) Nilai koefisien regresi variabel Motivasi Kerja terhadap Kinerja adalah sebesar 1,028. Hal ini berarti jika variabel Motivasi Kerja meningkat 1 satuan akan meningkatkan variabel Kinerja sebesar 1,028, dengan asumsi variabel Disiplin Kerja dianggap konstan.

\section{d. Koefisien Determinasi}

Tabel 10. Hasil Uji Determinasi

Disiplin Kerja (X1), dan Motivasi

Kerja (X2) terhadap Kinerja (Y) Model Summary

\begin{tabular}{|l|c|r|r|c|}
\hline $\begin{array}{l}\text { Mod } \\
\mathrm{el}\end{array}$ & $\mathrm{R}$ & $\begin{array}{c}\mathrm{R} \\
\text { Square }\end{array}$ & $\begin{array}{c}\text { Adjusted R } \\
\text { Square }\end{array}$ & $\begin{array}{c}\text { Std. Error } \\
\text { of the } \\
\text { Estimate }\end{array}$ \\
\hline 1 &, $809^{\mathrm{a}}$ &, 654 &, 641 & 2,091 \\
\hline
\end{tabular}

a. Predictors: (Constant), Motivasi, Disiplin

Berdasarkan tabel tersebut diatas yakni model summary yang menghasilkan nilai $\mathrm{R}$ sebesar 0,809 atau $80,9 \%$ yang berarti korelasi Disiplin Kerja dan Motivasi Kerja terhadap Kinerja pada kategori Sangat Kuat $(0,800$ - 1,00) dengan nilai koefisien determinasi adjusted $\mathrm{R}^{2}$ (adjusted $\mathrm{R}$ Square) sebesar 0.641. Hal ini menunjukan bahwa sebesar 64,1\% Disiplin Kerja dan Motivasi Kerja secara simultan (bersamasama) mempengaruhi Kinerja, sedangkan sisanya sebesar $35,9 \% \quad(100 \%$ $64,1 \%$ ) dipengaruhi oleh faktor lainnya yang tidak diteliti dalam penelitian ini.

\section{PENUTUP}

\section{A. Kesimpulan}

1. Secara parsial variabel Disiplin Kerja mempunyai pengaruh yang signifikan terhadap Kinerja.

2. Secara parsial variabel Motivasi Kerja mempunyai pengaruh yang signifikan terhadap Kinerja.

3. Diketahui uji $F$ diperoleh Fhitung 51,101 ini dapat dijelaskan bahwa pengaruh 
antara variabel Disiplin Kerja (X1), dan Motivasi Kerja (X2) secara simultan terhadap Kinerja (Y) positif dan signifikan karena nilai $F_{\text {hitung }}>$ nilai $F_{\text {tabel }}$ yaitu $51,101>2,70$ dan nilai signifikan $<0,05$ sehingga Ho ditolak $\mathrm{Ha}$ diterima. Berdasarkan model persamaan regresi linear berganda diperoleh persamaan $\mathrm{Y}=5,103+0,171 \mathrm{X} 1+$ 1,028X2, dimana dapat dijelaskan Nilai konstanta intersep sebesar 5,103 merupakan nilai konstanta (a). Nilai koefisien regresi variabel Disiplin Kerja terhadap Kinerja adalah sebesar 0,171. Hal ini berarti jika variabel Displin Kerja naik 1 satuan akan meningkat variabel Kinerja sebesar 0,171, dengan asumsi variabel Disiplin Kerja dan Motivasi Kerja dianggap konstan. Nilai koefisien regresi variabel Motivasi Kerja terhadap Kinerja adalah sebesar 1,028. Hal ini berarti jika variabel Motivasi Kerja meningkat 1 satuan akan meningkatkan variabel Kinerja sebesar 1,028, dengan asumsi variabel Disiplin Kerja dianggap konstan.

4. Sedangkan hasil uji koefisien determinasi diperoleh nilai $\mathrm{R}$ sebesar 0,809 atau $80,9 \%$ yang berarti korelasi Disiplin dan Motivasi Kerja terhadap Kinerja pada kategori Sangat Kuat $(0,800-1,00)$ dengan nilai koefisien determinasi adjusted $\mathrm{R}^{2}$ (adjusted $\mathrm{R}$ Square) sebesar 0.641. Hal ini menunjukan bahwa sebesar
64,1\% Disiplin Kerjadan Motivasi Kerja secara simultan (bersama-sama) mempengaruhi Kinerja, sedangkan sisanya sebesar 35,9\% dipengaruhi oleh faktor lainnya yang tidak diteliti dalam penelitian ini.

\section{B. Saran}

1. Pada variabel Disiplin Kerja, untuk lebih meningkatkan ketegasan dimana Pimpinan menggunakan nada langsung dalam berkomunikasi dengan bawahan

2. Pada variabel Motivasi Kerja agar lebih saling Menjaga perasaan antar sesama teman sejawat

3. Pada variabel kinerja agar lebih meningkatkan Kualitas Kerja, dimana Jumlah pekerjan yang dapat karyawan selesaikan setiap hari harus sesuai dengan target unit kerja.

4. Bagi peneliti selanjutnya disarankan untuk melakukan penelitian secara continue karena kontribusi disiplin kerja, motivasi kerja sangat mempengaruhi kinerja karyawan Peneliti boleh melakukan penelitian diluar varibel lain seperti: kompensasi, kepemimpinan. Jadi secara berkala boleh melakukan evaluasi disiplin kerja dan motivasi kerja tanpa mengesampingkan variabelvariabel yang lebih relevan dalam Rumah Sakit Umum Kota Tangerang Selatan.

\section{DAFTAR PUSTAKA}

A.A. Anwar Prabu Mangkunegara. 2017. Manajemen Sumber 
Daya Manusia Perusahaan.

Bandung: Remaja Rosdakarya

Agus Ali Suharto. 2012. Pengaruh

Kualitas Sumber Daya

Manusia, Komitmen Dan

Motivasi Terhadap Kinerja

Pegawai Pada Inspektorat

Kabupaten Kediri. Jurnal Ilmu

Manajemen, Revitalisasi, Vol.

1 , Nomor 3.

Alex S Nitisemito, 2012, Manajemen

Suatu Dasar dan Pengantar,

Arena Ilmu, Jakarta.

Anwar Prabu Mangkunegara. 2013.

Manajemen Sumber Daya

Manusia Perusahaan.

PT.Remaja Rosda Karya,

Bandung

Arikunto, Suharsimi. 2014. Prosedur

Penelitian Suatu Pendekatan

Praktik. Jakarta : Rineka

Cipta.

Gerry Dessler. 2012. Human

Resource Manamgement.

New jersey: Pearson

Education

Ghozali, Imam, 2016. Aplikasi Analisis Multivariate dengan Program SPSS Edisi Delapan. Semarang: Badan Penerbit Universitas Diponegoro

Greenberg, Jerald dan Baron, Robert

A. 2016. Perilaku Organisasi. Jakarta : Prentice Hall

Hasibuan Malayu, S.P., 2017. Manajemen Sumber Daya Manusia. Jakarta : Cetakan 18. PT. Bumi Aksara

Kreitner Robert dan Kinicki Angelo, 2016, Perilaku Organisasi, Edisi 9, Buku ke-2, Jakarta: Salemba Empat

Rivai, Veithzal. 2015, Manajemen Sumber Daya Manusia untuk Perusahaan: dari Teori ke
Praktik,Cetakan ke 7 Jakarta : Rajawali Pers

Sambas Ali Muhidin \& Maman Abdurahman. 2011. Dasardasar Metode Statistik Untuk Penelitian. Bandung: Pustaka Setia

Sedarmayanti. 2015. Sumber Daya Manusia dan Produktivitas Kerja. Jakarta: Mandar Maju. Sekaran, Uma dan Bougie, Roger. 2013. Research Methods for Business. United Kingdom: Jhon Wiley \& Sons Ltd.Singarimbun, Masri. 2012. Metode Penelitian Survei, Jakarta: LP3ES,

Sugiyono, 2012, Memahami Penelitian Kualitatif. Bandung : Alfabeta , 2014, Metode Penelitian Kombinasi (Mix Methods), Bandung: Alfabeta - 2014. Metode Penelitian Kuantitatif, Kualitatif, dan $R \& D$. Bandung: Penerbit Alfabeta.

Sunarsi, D. (2018). Pengaruh Gaya Kepemimpinan, Motivasi Dan Disiplin Kerja Terhadap Kinerja Pendidik Yayasan Marvin. INOVASI, 5(1), 118.

Supriyati. 2012. Belajar Akuntansi Dasar. Bandung: LABKAT PRESS UNIKOM

Wibowo, 2016. Manajemen Kinerja, Edisi Kelima,PT.Rajagrafindo Persada Jakarta-14240. 